Journal of Animal and Veterinary Advances 11 (11): 1771-1773, 2012

ISSN: $1680-5593$

(C) Medwell Journals, 2012

\title{
Gastrin-Releasing Peptide (GRP) in the Uteroplacenta of the Sika Deer (Cervus nippon)
}

\author{
JoonHyukSohn and Junpei Kimura \\ Department of Veterinary Anatomy and Cell Biology, College of Veterinary Medicine, \\ Seoul National University, 599 Gwanangno, Gwanak-Gu, 151-742 Seoul, Republic of Korea
}

\begin{abstract}
The localization of GRP in the uterus and/or placenta of non-pregnant or pregnant Sika deer was studied immunohistochemically. The strong immunoreactions were identified in the supra-nuclear region of the epithelial cells of the uterine glands of the placenta, however, no reaction was observed in the uterus of nonpregnant or immature animals. GRP may play an important role as the critical signals or nutrients for the growth of fetus in the synepitheliochorial placenta.
\end{abstract}

Key words: Immunolocalization, GRP, Sika deer, uterus, placenta, Japan

\section{INTRODUCTION}

The study of the Sika deer has been done by several points of view including the reproductive status (Suzuki and Ohtaishi, 1993), the testicular and ovarian histology (Hayakawa et al., 2004), the anatomical study (Ozaki et al., 2004), the endocrine study (Takahashi et al., 2002) and phylogenetic study (Nagata et al., 1999). The necessity of the reproductive study of Sika deer can be emphasized for the accumulation of the basic reproductive information for the purpose of the artificial control of the over populated Sika deer in Japan. The emphasize will be also pointed for the conservation and artificial production of endangered Sika species in several countries including China and Vietnam.

The Gastrin-Releasing Peptide (GRP) has been know to regulates numerous central nervous and gastrointestinal functions (Lesniewska et al., 2001). The important role of GRP including the modulation of uterine contraction (Amiot et al., 1993), the control of epithelial ion transport in the endometrium (Matthews et al., 1993) and an autocrine and paracrine regulation in the uterus (Vetter and O'Grady, 1997) has been suggested. The GRP immunolocalization has been studied in human (Xiao et al., 1996), sheep (Fraser et al., 2004), cattle (Budipitojo et al., 2001) and mouse deer (Kimura et al., 2006) and the localization in the uterine epithelium were demonstrated. However, no studies has been done in any cervid species.

This study was designed to clarify the physiological role of the uteroplacenta of Sika deer by using a GRP as an indicator to compare with other ruminants. Such information is a necessary prerequisite for design of effective strategies for the management and conservation of this species.

\section{MATERIALS AND METHODS}

Totally 28 female Sika deer were used in this study. Sika deer were killed by the rifle or shotgun shots for the culling for the purpose of the population control or the pleasure hunting in the Tanzawa-Oyama Kanagawa Prefectual Natural Park, Japan during November to March of 2004-2006. Among the twenty eight deer, the existence of the fetus were macroscopically recognized in three individuals and the Hind Foot Length (HFL) of the fetus were $16.5 \mathrm{~mm}$ in No.: $804045,97.5 \mathrm{~mm}$ in No.: 804046 and $119.5 \mathrm{~mm}$ in No.: 804020 . Uteri were excised and fixed in $10 \%$ formalin or Bouin's solution. They were dissected and samples were dehydrated, embedded in paraffin and stained immunohistochemically using the avidin-biotinperoxidase complex method (Hsu et al., 1981) with the antisera to porcine GRP raised in the rabbit (Yanaihara Institute Inc., Shizuoka, Japan, Code Y160). Briefly, after an overnight incubation at $4^{\circ} \mathrm{C}$ with the primary antiserum (x10,000 dilution), sections were incubated with biotinylated anti rabbit immunoglobulins (Nichirei, Tokyo, Japan) for $30 \mathrm{~min}$. Following this step, the avidin-biotinperoxidase complex was applied to the sections for $5 \mathrm{~min}$. A brown reaction product was obtained by subsequently incubating the sections in diaminobenzidine- $\mathrm{H}_{2} \mathrm{O}_{2}$ solution. Staining controls included the omission of

Corresponding Author: Junpei Kimura, Department of Veterinary Anatomy and Cell Biology, College of Veterinary Medicine, Seoul National University, 599 Gwanangno, Gwanak-Gu, 151-742 Seoul, Republic of Korea 
the primary antiserum. All stained sections were observed by light microscope attached with a digital camera (Coolscope, Nikon, Tokyo, Japan).

\section{RESULTS AND DISCUSSION}

Binucleated cells which is common and unique for ruminat placenta were identified at the trophoblast (Chorionic epithelium) of placenta in Sika deer as reported in other deer species like Roe deer, Fallow deer, Chinese water deer, Muntjac deer, Red deer and Axis deer (Wooding, 1982). From this finding, the placenta of Sika deer can be classified as a synepitheliochorial placenta, a mixture of maternofetal hybrid synepithelium with cellular uterine epithelium apposed to fetal cellular trophectoderm.

The crossreaction of antisera to porcine GRP with the uteroplacental tissue of Sika deer was verified. In the uteri of the immature (No.: 804023, Fig. 1) and non pregnant (No.: 804022, Fig. 2) Sika deer, the immunoreaction for the GRP was not detected. On the other hand, strong positive reactions were detected in the uterine glands of the all pregnant Sika deer (No.: 804045, Fig. 3a and b, No.: 804020, Fig. 3c and d).

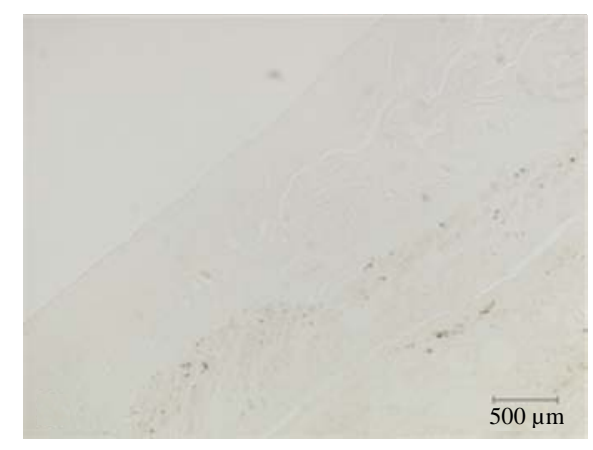

Fig. 1: Negative GRP immunoreaction in the endometrial glands of immature Sika deer (No.: 804023)

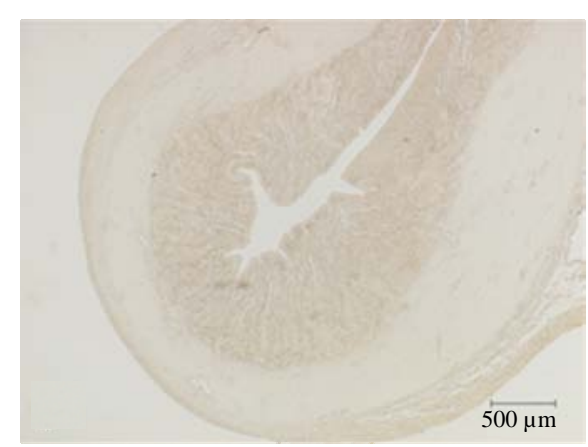

Fig. 2: Very weak or negative immunoreaction of GRP in the endometrial glands of the non-pregnant mature Sika deer (No.: 804022)
The supra nuclear region of the uterine epithelial glandular epithelial cells show vividly positive reaction for the GRP antibody (Fig. 3b and d). Uterine epithelial cells, stromal and muscular layer did not show positive reactions. The localization of GRP in the supra nuclear region of the uterine glands suggests that GRP was released from the cells into the lumen of the gland by exocrine manner. This was also evident in the cow at light and electron-microscopic levels (Budipitojo et al., 2001, 2003) and in the mouse deer at light-microscopic level (Kimura et al., 2006).

The immunoreacvitiy of GRP in the endometrial glands was much stronger in the pregnant individuals, regardless of the size of fetus (HFL 16.5-119.5 mm). On the other hand in the uterus where no fetus was observed macroscopically, the GRP immunoreactivity was negative (Fig. 1 and 2).

GRP immunoreactivity in the reproductive system has been detected during human pregnancy, predominantly in the trophoblasts of placental villi, extravillous trophoblasts and amniotic epithelial cells (Xiao et al., 1996). In sheep and cattle, it has been reported both in non-pregnant and pregnant animals, predominatly in the uterine gland epithelial cells which show immunolocalization by this peptide (Budipitojo et al., 2001).

This study is the first to show the immunoreaction of GRP in the animals belonging to Cervidae family. This result indicate that the GRP plays an important role as the critical signals or nutrients for the growth of fetus especially in the pregnant period. In previous results, the GRP is identified positively in the pregnant uterus and weakly or negatively in the non pregnant uterus in the mouse deer (Kimura et al., 2006). Although, there is the

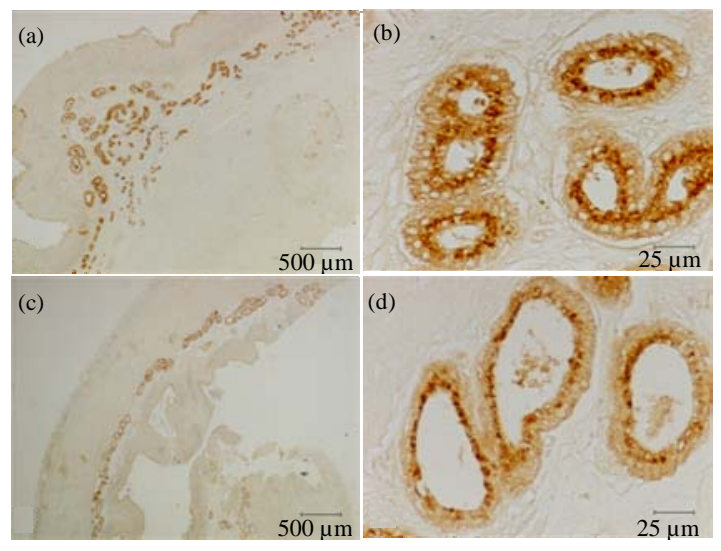

Fig. 3: a-d) Strong positive immunoreaction of GRP in the supra nuclear region of the endometrial glandular epithelial cells of the pregnant Sika deer ( $a, b ;$ No.: 804045 and c, d; No.: 804020) 
differences in the level of suborder between Sika deer (Pecora) and Mouse deer (Tragulina), Sika deer as the seasonal breeder is showing the much clearer differences of the immunohistochemical reactivity between pregnant and non pregnant stage compared to the mouse deer as non seasonal breeder.

This speculation can be adopted to the difference between Sika deer and cow which both are belongings to suborder Pecora. In the cow the weakly positive reaction of GRP can be observed even in the non pregnant uterus (Budipitojo et al., 2003). It was revealed in the cow that RT-PCR showed GRP mRNA fragments in the tissue during all stages of the cycle (Budipitojo et al., 2003). Positive staining of GRP immunoreactivity in the uterine gland epithelial cells was also detected in both the uterine horn and body during all stages of the cycle in the cow (Budipitojo et al., 2003). Sika deer delives only one time in the year in Japan. On the other hand, cow in the captivity in Japan possesses multiple breeding season in a year. The difference of the existence of the breeding seasonality may cause the clear difference in the expression the GRP in the uterus.

\section{CONCLUSION}

The strong immunoreactions were identified in the epithelial cells of the uterine glands of the placenta in the Sika deer. GRP may play an important role as the critical signals or nutrients for the growth of fetus in the synepitheliochorial placenta.

\section{REFERENCES}

Amiot, F., D. Leiber, S. Marc and S. Harbon, 1993. GRP-preferring bombesin receptors increase generation of inositol phosphates and tension in rat myometrium. Am. J. Physiol., 265: 1579-1587.

Budipitojo, T., M. Sasaki, S. Matsuzaki, M.B. Cruzana, T. Iwanaga, N. Kitamura and J. Yamada, 2003. Expression of Gastrin-Releasing Peptide (GRP) in the bovine uterus during the estrous cycle. Arch. Histol. Cytol., 66: 337-346.

Budipitojo, T., S. Matsuzaki, M.B.C. Cruzana, E.T. Baltazar and E. Hondo et al., 2001. Immunolocalization of gastrin-releasing peptide in the bovine uterus and placenta. J. Vet. Med. Sci., 63: 11-15.

Fraser, M., T.J. McDonald, E.R. Spindel, M. Fahy, D. Hill and J.R.G. Challis, 2004. Gastrin-releasing peptide is produced in the pregnant ovine uterus. Endocrinology, 135: 2440-2445.

Hayakawa, D., M. Sasaki, C. Akabane, N. Kitamura, T. Tsubota, M. Suzuki and J. Yamada, 2004. Immunohistochemical localization of steroidogenic enzymes in the testis of Hokkaido Sika deer (Cervus nippon yesoensis). J. Vet. Med. Sci., 66: 1463-1466.
Hsu, S.M., L. Raine and H. Fanger, 1981. Use of avidin-biotin peroxidase complex $(\mathrm{ABC})$ in immunoperoxidase techniques: A comparison between $\mathrm{ABC}$ and unlabelled antibody (PAP) procedures. J. Histochem. Cytochem., 29: 577-580.

Kimura, J., T. Budipitojo, M. Sasaki, N. Kitamura, J. Yamada, H. Endo and K. Fukuta, 2006. Immunolocalization of Gastrin-Releasing Peptide (GRP) in the uteroplacenta of the mouse deer. Anat. Histol. Embryol., 35: 217-220.

Lesniewska, V., A. Gregard, B. Westrom, M.S. Hedemann, H.N. Laerke, D. Kruszewska and S.G. Pierzynowski, 2001. The role of cholinergic and peptidergic pathways in the regulation of pancreatic exocrine function during postnatal development in pigs. Exp. Physiol., 86: 399-409.

Matthews, C.J., C.P. Redfern, E.J. Thomas and B.H. Hirst, 1993. Bombesin and gastrin-releasing peptide stimulate electronic ion transport in cultured human endometrial epithelial cell layers. Exp. Physiol., 78: 715-718.

Nagata, J., R. Masuda, H.B. Tamate, S. Hamasaki and $\mathrm{K}$. Ochiai et al., 1999. Two genetically distinct lineages of the sika deer, Cervus nippon, in Japanese islands: comparison of mitochondrial D-loop region sequences. Mol. Phylogenet. Evol., 135: 511-519.

Ozaki, N., M. Suzuki and N. Ohtaishi, 2004. Histological variations in myoepithelial cells and arrectores pilorum muscles among caudal, metatarsal and preorbital glands in Hokkaido sika deer (Cervus nippon yesoensis Heude, 1884). J. Vet. Med. Sci., 66: $283-285$

Suzuki, M. and N. Ohtaishi, 1993. Reproduction of female Sika deer (Cervus nippon yesoensis Heude, 1884) in Ashoro district, Hokkaido. J. Vet. Med. Sci., 55: 833-836.

Takahashi, T., S. Hamanaka, K. Imai and K. Hashizume, 2002. Fecal progesterone analysis by time-resolved fluoroimmunoassay (TR-FIA) for monitoring of luteal function in the sika deer (Cervus nippon centralis). J. Vet. Med. Sci., 64: 565-569.

Vetter, A.E. and S.M. O'Grady, 1997. Mechanisms of electrolyte transport across the endometrium. II. Regulation by GRP and substance P. Am. J. Physiol., 273: $67-76$.

Wooding, F.B., 1982. The role of the binucleated cell in ruminant placental structure. J. Reprod. Fertil. Suppl., 31: $31-39$.

Xiao, Q., X. Han, J.R. Challis, D.J. Hill and E.R. Spindel et al., 1996. Gastrin-releasing peptide-like immunoreactivity is present in human maternal and fetal placental membranes. J. Clin. Endocrinol. Metab., 81: 3766-3773. 